\title{
Exercise of low energy expenditure along with mild energy intake restriction acutely reduces fasting and postprandial triacylglycerolaemia in young women
}

\author{
Maria Maraki, Nektarios Christodoulou, Niki Aggelopoulou, Faidon Magkos, Katerina P. Skenderi, \\ Demosthenes Panagiotakos, Stavros A. Kavouras and Labros S. Sidossis* \\ Laboratory of Nutrition \& Clinical Dietetics, Department of Nutrition and Dietetics, Harokopio University, 70 El. Venizelou Ave, \\ Athens 176-71, Greece
}

(Received 12 December 2007 - Revised 7 April 2008 - Accepted 6 May 2008 - First published online 23 June 2008)

A single bout of prolonged, moderate-intensity endurance exercise lowers fasting and postprandial TAG concentrations the next day. However, the TAG-lowering effect of exercise is dose-dependent and does not manifest after light exercise of low energy cost $(<2 \mathrm{MJ})$. We aimed to investigate whether superimposing mild energy intake restriction to such exercise, in order to augment total energy deficit, potentiates the hypotriacylglycerolaemic effect. Eight healthy, sedentary, premenopausal women (age 27.1 (SEM 1.3) years; BMI 21.8 (SEM 0.9) $\mathrm{kg} / \mathrm{m}^{2}$ ) performed two oral fat tolerance tests in the morning on two different occasions: once after a single bout of light exercise (100 min at $30 \%$ of peak oxygen consumption; net energy expenditure 1.04 (SEM 0.01) MJ) coupled with mild energy intake restriction (1.39 (SEM 0.22) MJ) on the preceding day, and once after resting coupled with isoenergetic feeding on the preceding day (control). Fasting plasma TAG, TAG in the TAG-rich lipoproteins (TRL-TAG) and serum insulin concentrations were 18,34 and 30\% lower, respectively, after exercise plus diet compared with the control trial $(P<0 \cdot 05)$. Postprandial concentrations of plasma TAG and TRL-TAG were 19 and $27 \%$ lower after exercise plus diet compared with the control condition $(P<0 \cdot 01)$, whereas postprandial insulin concentrations were not different. It is concluded that a combination of light exercise along with mild hypoenergetic diet may be a practical and feasible intervention to attenuate fasting and postprandial triacylglycerolaemia, especially for people who cannot exercise for prolonged periods of time at moderate-to-high intensities, such as many sedentary individuals.

Postprandial lipaemia: Exercise: Diet: Triacylglycerol

CHD is the leading cause of death in industrialized countries $^{(1,2)}$. Elevated levels of fasting ${ }^{(3,4)}$ and postprandial $^{(5,6)}$ TAG are associated with increased risk for atherosclerosis; therefore, interventions that decrease or prevent an increase in plasma TAG concentrations may be valuable in reducing the risk of CHD. Aerobic exercise has been shown to lower plasma TAG concentrations in the fasting as well as in the postprandial state ${ }^{(7)}$. The hypotriacylglycerolaemic effect of exercise manifests acutely, approximately $12 \mathrm{~h}$ after the cessation of a single exercise bout, lasts for 1-2 d and does not seem to result from metabolic adaptations to repeated exercise sessions (i.e. training) $)^{(7-9)}$

Accumulating evidence suggests that the TAG-lowering effect of exercise depends on the energy expended during the exercise bout ${ }^{(7,10)}$ and is only evident with an accompanying negative energy balance ${ }^{(11)}$. Single, prolonged sessions of moderate-intensity exercise $(\geq 90 \mathrm{~min}$ at $\geq 60 \%$ of peak oxygen consumption, $\mathrm{V}_{\mathrm{O} \text { 2peak }}$, corresponding to gross energy expenditures $\geq 3 \mathrm{MJ}$, decrease plasma TAG concentrations the next day by $15-26 \%$ in the fasting state ${ }^{(12-15)}$ and by $16-34 \%$ in the postprandial state ${ }^{(12-14,16-19)}$. However, when the exercise duration is shorter $(\leq 60 \mathrm{~min})^{(20,21)}$, or the exercise intensity is lower $\left(\leq 30 \% \text { of } \mathrm{V}_{\mathrm{O} 2 \text { peak }}\right)^{(18,22)}$, corresponding to gross energy expenditures $<2 \mathrm{MJ}$, fasting and postprandial plasma TAG concentrations are not altered. The intensity of exercise per se does not appear to play a key role, since manipulating the intensity and duration of exercise while keeping total energy expenditure of the exercise bout constant does not affect plasma TAG response to exercise ${ }^{(19,23)}$. Even exercise of low intensity ( $30 \%$ of $\mathrm{V}_{\text {O2peak }}$ ) is effective in reducing fasting and postprandial TAG concentrations the next day when performed for $2-3 \mathrm{~h}$ (total energy expenditure 3.0$4 \cdot 2 \mathrm{MJ})^{(19,24)}$, but not when performed for shorter time (about $90 \mathrm{~min}$; total energy expenditure $1 \cdot 6-1 \cdot 7 \mathrm{MJ})^{(18,25)}$. These data indicate that the energy expenditure threshold for exerciseinduced lowering of plasma TAG concentrations lies around 2-3 MJ (in a single bout), which corresponds to 60-90 $\mathrm{min}$ of exercise at $60 \%$ of $\mathrm{V}_{\text {O2peak }}{ }^{(26)}$. Unfortunately, most sedentary individuals will have difficulties exercising at this intensity for so long ${ }^{(27,28)}$, while exercising at lower intensities for prolonged periods of time, e.g. $3 \mathrm{~h}$, is clearly impractical ${ }^{(28,29)}$.

Although exercise of low energy expenditure (approximately $1.5 \mathrm{MJ}$ ) has been shown not to affect fasting and postprandial plasma TAG concentrations ${ }^{(18,20,21,25)}$, it is currently

Abbreviations: HOMA-IR, homeostasis model assessment of insulin resistance; LPL, lipoprotein lipase; OFTT, oral fat tolerance test; TRL, TAG-rich lipoproteins;

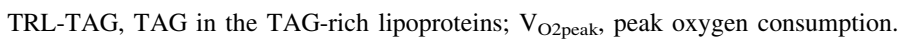

* Corresponding author: Dr Labros S. Sidossis, fax +30210954 9141, email 1sidossis@hua.gr 
not known whether the addition of mild energy intake restriction (approximately $1.5 \mathrm{MJ}$ ) on top of such exercise could potentiate the manifestation of hypotriacylglycerolaemia. We therefore sought to evaluate fasting and postprandial TAG responses to acute negative energy balance, induced partly by a single bout of exercise of low energy cost and partly by mild hypoenergetic feeding, in young, healthy, sedentary women.

\section{Methods}

\section{Subjects}

Eight healthy, lean, young premenopausal women participated in the study; they were all normolipidaemic and normoglycaemic (Table 1). Exclusion criteria included contraindication to aerobic exercise, pregnancy, acute or chronic illness, use of medications (including oral contraceptives) or dietary supplements, smoking, regular exercise participation (two or more times per week) and being on a special diet or having experienced weight fluctuations $>2 \mathrm{~kg}$ during the last 6 months. The experimental protocol was approved by the Ethics Committee of Harokopio University, Athens, and all subjects signed informed consent.

\section{Preliminary testing}

During their first visit to the laboratory, subjects gave a fasting blood sample for biochemical analyses. Height was measured with a stadiometer (Holtain, UK) and body weight was measured on a medical beam scale (Seca, Germany). Body composition (fat mass and fat-free mass) was determined by dual-energy X-ray absorptiometry (model DPXMD; Lunar, Madison, WI, USA) using software version 4.6 and a $15 \mathrm{~min}$ scan time. Resting energy expenditure was measured by indirect calorimetry using a ventilated hood system (Sensormedics, Vmax229; Yorba Linda, CA), after the subjects had rested for about $30 \mathrm{~min}$.

In a separate visit, $\mathrm{V}_{\mathrm{O} \text { peak }}$ was determined using a submaximal incremental brisk walking test ${ }^{(30)}$. Subjects walked on a treadmill (Technogym Runrace; Gambettola, Italy) at constant speed $(5.0-6.5 \mathrm{~km} / \mathrm{h})$, and the grade was increased by $2 \%$ every $2 \mathrm{~min}$. Heart rate was monitored continuously by a

Table 1. Subject characteristics $(n 8)$

(Mean values with their standard errors)

\begin{tabular}{|c|c|c|}
\hline & Mean & SEM \\
\hline Age (years) & $27 \cdot 1$ & $1 \cdot 3$ \\
\hline Body weight $(\mathrm{kg})$ & 62.9 & $3 \cdot 3$ \\
\hline $\operatorname{BMI}\left(\mathrm{kg} / \mathrm{m}^{2}\right)$ & $21 \cdot 8$ & 0.9 \\
\hline Body fat $(\%)$ & $27 \cdot 1$ & $3 \cdot 2$ \\
\hline Absolute $\mathrm{V}_{\text {O2peak }}$ (litres/min) & $2 \cdot 2$ & $0 \cdot 1$ \\
\hline Relative $\mathrm{V}_{\text {O2peak }}(\mathrm{ml} / \mathrm{min}$ per $\mathrm{kg} \mathrm{BW})$ & $35 \cdot 3$ & $1 \cdot 7$ \\
\hline Resting energy expenditure (MJ/d) & $5 \cdot 18$ & 0.27 \\
\hline $\mathrm{TAG}(\mathrm{mmol} / \mathrm{l})$ & 0.78 & 0.07 \\
\hline Total cholesterol (mmol/l) & 4.56 & 0.22 \\
\hline HDL-cholesterol (mmol/l) & $1 \cdot 14$ & $0 \cdot 11$ \\
\hline Glucose (mmol/l) & $5 \cdot 26$ & $0 \cdot 10$ \\
\hline
\end{tabular}

$\mathrm{V}_{\text {O2peak, }}$ peak oxygen consumption. telemetric heart rate monitor (Polar Accurex Plus, Finland). Expiratory gases were measured continuously with a breathby-breath gas analyzer system (Sensormedics, Vmax229). The test was terminated at $80 \%$ of heart rate reserve ${ }^{(31)}$ and $\mathrm{V}_{\mathrm{O} 2 \text { peak }}$ was predicted from the $\mathrm{V}_{\mathrm{O} 2}$-heart rate relationship.

\section{Study design}

All subjects performed two trials (control and exercise plus diet) in random order; an oral fat tolerance test (OFTT) was administered the day following each intervention. All trials were carried out in the follicular phase of the menstrual cycle ${ }^{(32)}$. Subjects were asked to refrain from exercise and carry out only the activities of daily living for the $2 \mathrm{~d}$ prior to each intervention day.

Control. For the control trial, subjects were asked to refrain from exercise and carry out only the activities of daily living. During the afternoon of the day preceding the OFTT, all subjects remained rested at home, i.e. sat in a chair or laid in bed while reading, watching television or listening to music. They also followed a prescribed diet which provided their estimated energy needs, calculated by multiplying the measured resting energy expenditure with an activity factor of $1.3-1.5$, representative of the very light to light habitual physical activity patterns of our subjects ${ }^{(33)}$.

Exercise plus diet. For the exercise plus diet trial, subjects were asked to refrain from exercise and carry out only the activities of daily living, with the exception of the exercise session at the laboratory on the afternoon before the OFTT. Each subject attended the laboratory during the afternoon (midway between lunch and dinner) and walked on the treadmill (Technogym Runrace) for $100 \mathrm{~min}$. During exercise, oxygen consumption was measured every $15 \mathrm{~min}$ and the grade was adjusted, if necessary, in order for each subject to exercise at $30 \%$ of her $\mathrm{V}_{\text {O2peak }}$. Moreover, subjects followed a prescribed diet which provided their estimated energy needs (without accounting for the exercise-induced increase in energy expenditure) minus about $1.4 \mathrm{MJ}$ (diet-induced energy deficit). The restriction of energy intake occurred at the lunch meal, afternoon snack and dinner meal.

\section{Dietary analysis}

Subjects were asked to follow a prescribed diet during each intervention day that was designed to provide $50 \%$ of energy from carbohydrate, $35 \%$ from fat and $15 \%$ from protein. The energy intake during the exercise plus diet trial was designed to be approximately $1.4 \mathrm{MJ}$ lower than that during the control trial. This dietary energy deficit was equivalent to the estimated gross energy expenditure of the exercise session, so that approximately one half of the total energy deficit in the exercise plus diet trial (relative to the control trial) was due to reduced energy intake and the other half due to increased exercise energy expenditure. To ensure compliance to the prescribed diets subjects were asked to record their food intake. Food records for each intervention day and for the day prior to each intervention day were analysed using Nutritionist V diet analysis software (FirstDataBank, San Bruno, CA, USA). 


\section{Oral fat tolerance test}

The morning following each intervention, responses to a standard high-fat meal were assessed. Subjects arrived at the laboratory after a $12 \mathrm{~h}$ fast, at approximately 07.30 hours. A cannula was introduced into a forearm or antecubital vein and the subject rested quietly in the seated position for $15 \mathrm{~min}$, after which a baseline fasting blood sample $(t 0 \mathrm{~h})$ was obtained. The test meal was then consumed within $15 \mathrm{~min}$. Additional blood samples were obtained at 30 and $60 \mathrm{~min}$ and then hourly until $6 \mathrm{~h}$ after completion of the test meal. The cannula was flushed with heparin-free $\mathrm{NaCl}$ $(0.9 \%)$ every $30 \mathrm{~min}$ to keep it patent. Subjects remained rested in the seated position (while reading, watching television or listening to music) throughout the $6 \mathrm{~h}$ postprandial period. They were able to go to the restroom at any time, with the exception of a $15 \mathrm{~min}$ period prior to each blood sampling. They consumed only mineral water, which was provided ad libitum during the first OFTT and replicated in the subsequent OFTT. The test meal was given as a milkshake consisting of whipping cream, vanilla ice cream and syrup ( $1.2 \mathrm{~g}$ fat, $1.1 \mathrm{~g}$ carbohydrate, $0.2 \mathrm{~g}$ protein $/ \mathrm{kg}$ body weight $)^{(34)}$. Oxygen uptake and carbon dioxide production during the OFTT were measured (Sensormedics, Vmax229) for $15 \mathrm{~min}$ before and every hour after meal consumption.

\section{Analytical methods}

Blood samples taken before and during the OFTT were collected into non-heparinized serum tubes (Sarstedt, Leicester, UK), allowed to clot, spun in a centrifuge, and then aliquoted and frozen immediately at $-80^{\circ} \mathrm{C}$ until analysis. Separate blood samples for plasma preparation were collected into precooled potassium-EDTA Monovettes (Sarstedt), spun immediately in a refrigerated centrifuge within $15 \mathrm{~min}$, aliquoted and frozen immediately at $-80^{\circ} \mathrm{C}$ until analysis. One aliquot of fresh plasma was kept on ice overnight before separation of the TAG-rich lipoproteins (TRL). The TRL fraction $\left(\mathrm{S}_{\mathrm{f}} \geq 20\right)$ was separated as previously described ${ }^{(35)}$, by slicing the tube and collecting the upper part after preparative ultracentrifugation for $300 \mathrm{~min}$ at $61000 \mathrm{rpm}$ at $4^{\circ} \mathrm{C}$, in an Optima TLX ultracentrifuge equipped with the fixed angle MLA-80 rotor (Beckman Instruments, Palo Alto, CA, USA).

Determination of plasma TAG, glucose, NEFA, total cholesterol and HDL-cholesterol was performed by enzymatic colorimetric methods using commercially available enzymatic kits (Alfa Wassermann Diagnostics, Woerden, The Netherlands) on an automated analyser (ACE Schiapparelli Biosystems, Fairfield, IN, USA). Serum insulin was measured with an immunoenzymetric fluorescent method using a commercially available kit (ST AIA-PACK IRI; Tosoh Medics, San Francisco, CA, USA) on an automated analyser (Tosoh AIA 600II; Tosoh Medics). All samples from each subject's two trials were analysed in the same batch.

\section{Indirect calorimetry and energy expenditure calculations}

Oxygen uptake and carbon dioxide production during exercise and OFFT were measured with a breath-by-breath gas analyser system (Sensormedics, Vmax229). Energy expenditure, fat and carbohydrate oxidation were calculated using the Weir formula ${ }^{(36)}$ and a table for non-protein $\mathrm{RQ}^{(37)}$, assuming that urinary nitrogen excretion was negligible. Net energy expenditure of exercise was calculated by subtracting values for energy expenditure during rest $(100 \mathrm{~min})$ from the corresponding gross energy expenditure values during the exercise session.

\section{Calculations and statistics}

Whole-body insulin sensitivity was assessed by the homeostasis model assessment of insulin resistance (HOMA-IR) index as: fasting serum insulin $(\mu \mathrm{U} / \mathrm{ml}) \times$ fasting plasma glucose $(\mathrm{mmol} / \mathrm{l}) / 22 \cdot 5^{(38)}$. The concentration of LDL-cholesterol was calculated according to the Friedewald equation as: LDL-cholesterol $=$ total cholesterol - HDL-cholesterol $\mathrm{TAG} / 2 \cdot 2^{(39)}$. Total and incremental (above the fasting concentration) areas under the concentration $v$. time curves were calculated using the trapezoidal rule, and are referred to as total and incremental response, respectively. The highest value during the postprandial period is referred to as peak response.

Normality of data was graphically explored using percentile-plots. Comparisons between trials for postprandial responses were made by using repeated measures ANOVA. Means for dietary data, fasting variables, total, incremental and peak responses were compared using Student's paired $t$ tests if data were normally distributed, or Wilcoxon's signed rank tests if data were not normally distributed. Data are expressed as means and their standard errors. Statistical significance was set at the $5 \%$ level $(P \leq 0 \cdot 05)$. Results were analysed using SPSS statistical software version 13.0 (SPSS Inc., Chicago, IL, USA).

\section{Results}

\section{Exercise session and dietary intake}

Average oxygen consumption during the exercise session was 0.66 (SEM 0.03) litres/min, which corresponded to 30.2 (SEM 0.8)

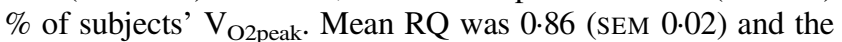
gross energy expenditure of exercise was 1.41 (SEM 0.02) MJ, with 55 (SEM 6) \% originating from carbohydrate oxidation and 45 (SEM 6) $\%$ from fat oxidation. The net energy expenditure of exercise was 1.04 (SEM 0.01) MJ.

By design, energy intake during the exercise plus diet trial was lower than during the control intervention (5.75 (SEM 0.63 ) and 7.14 (SEM 0.65) MJ, respectively; $P<0.001$ ), while percentages of energy derived from protein, carbohydrate and fat were not significantly different between the two trials $(P>0.05)$.

Therefore, compared to the control trial (zero energy balance), there was an energy deficit of 2.44 (SEM 0.22) MJ during the exercise plus diet trial.

\section{Responses in the fasted state}

Fasting concentrations of plasma TAG, TAG in the TAG-rich lipoproteins (TRL-TAG), total cholesterol, HDL- and LDLcholesterol, glucose, NEFA, serum concentrations of insulin and the HOMA-IR index are shown in Table 2. Fasting plasma TAG, TRL-TAG and serum insulin concentrations were approximately 18, 34 and $30 \%$ lower, respectively, after 
Table 2. Fasting plasma concentrations of substrates, serum insulin and homeostasis model assessment of insulin resistance (HOMA-IR) the day after the control and exercise plus diet interventions*

(Mean values with their standard errors)

\begin{tabular}{|c|c|c|c|c|c|}
\hline & \multicolumn{2}{|c|}{ Control } & \multicolumn{2}{|c|}{$\begin{array}{l}\text { Exercise plus } \\
\text { diet }\end{array}$} & \multirow[b]{2}{*}{$P$ value } \\
\hline & Mean & SEM & Mean & SEM & \\
\hline Total TAG $(\mathrm{mmol} / \mathrm{l})$ & 0.82 & 0.07 & 0.67 & 0.04 & 0.023 \\
\hline TRL-TAG (mmol/l) & 0.41 & 0.05 & 0.27 & 0.05 & 0.014 \\
\hline Total cholesterol (mmol/l) & $4 \cdot 47$ & 0.19 & 4.46 & 0.23 & 0.991 \\
\hline HDL-cholesterol (mmol/l) & $1 \cdot 10$ & $0 \cdot 10$ & $1 \cdot 12$ & 0.11 & 0.371 \\
\hline LDL-cholesterol (mmol/l) & 2.99 & $0 \cdot 15$ & 3.03 & $0 \cdot 19$ & 0.744 \\
\hline Glucose $(\mathrm{mmol} / \mathrm{l})$ & $5 \cdot 21$ & 0.17 & $5 \cdot 14$ & 0.12 & 0.239 \\
\hline NEFA (mmol/l) & 0.53 & 0.07 & 0.56 & 0.06 & 0.614 \\
\hline Insulin (pmol/l) & $35 \cdot 0$ & $4 \cdot 3$ & $24 \cdot 5$ & $3 \cdot 1$ & 0.028 \\
\hline HOMA-IR & $1 \cdot 16$ & 0.14 & 0.80 & 0.10 & 0.025 \\
\hline
\end{tabular}

TRL-TAG, TAG in the TAG-rich lipoproteins.

${ }^{\star}$ For details of subjects and procedures, see Methods and Table 1.

exercise plus diet compared with the control trial $(P<0 \cdot 05)$. There were no significant differences between trials in fasting total cholesterol, HDL- and LDL-cholesterol, glucose and NEFA concentrations $(P>0.05)$. Insulin resistance (HOMA-IR) was approximately $31 \%$ lower the morning after exercise plus diet than after the control intervention $(P<0 \cdot 05)$.

Data for oxygen consumption, resting metabolic rate and substrate utilization in the fasted state are shown in Table 3; there were no significant differences between trials $(P>0.05)$.

Postprandial responses

Plasma TAG and TRL-TAG concentrations during the postprandial period are shown in Fig. 1. ANOVA for repeated measures revealed that postprandial plasma TAG and

Table 3. Fasting and postprandial oxygen consumption, $R Q$, energy expenditure and substrate utilization the day after the control and exercise plus diet interventions*

(Mean values with their standard errors)

\begin{tabular}{|c|c|c|c|c|c|}
\hline & \multicolumn{2}{|c|}{ Control } & \multicolumn{2}{|c|}{$\begin{array}{l}\text { Exercise plus } \\
\text { diet }\end{array}$} & \multirow[b]{2}{*}{$P$ valu } \\
\hline & Mean & SEM & Mean & SEM & \\
\hline \multicolumn{6}{|l|}{ Fasting } \\
\hline $\mathrm{V}_{\mathrm{O} 2}$ (litres/min) & 0.18 & 0.01 & 0.17 & 0.01 & 0.224 \\
\hline $\mathrm{RQ}$ & 0.86 & 0.02 & 0.83 & 0.02 & $0 \cdot 124$ \\
\hline $\begin{array}{l}\text { Energy expenditure } \\
\qquad(\mathrm{MJ} / \mathrm{h})\end{array}$ & 0.23 & 0.01 & 0.21 & 0.01 & $0 \cdot 164$ \\
\hline $\begin{array}{l}\text { Carbohydrate oxidation } \\
(\mathrm{g} / \mathrm{h})\end{array}$ & $7 \cdot 69$ & $1 \cdot 34$ & $5 \cdot 75$ & $1 \cdot 14$ & 0.092 \\
\hline Fat oxidation $(\mathrm{g} / \mathrm{h})$ & $2 \cdot 47$ & 0.41 & 2.99 & 0.33 & 0.179 \\
\hline \multicolumn{6}{|l|}{ Postprandial } \\
\hline $\mathrm{V}_{\mathrm{O} 2}$ (litres/min) & 0.18 & 0.01 & 0.18 & 0.01 & 0.924 \\
\hline $\mathrm{RQ}$ & 0.83 & 0.02 & 0.80 & 0.01 & 0.086 \\
\hline $\begin{array}{l}\text { Energy expenditure } \\
(\mathrm{MJ} / \mathrm{h})\end{array}$ & 0.22 & 0.01 & 0.22 & 0.01 & 0.687 \\
\hline $\begin{array}{l}\text { Carbohydrate oxidation } \\
(\mathrm{g} / \mathrm{h})\end{array}$ & $6 \cdot 49$ & 1.01 & $4 \cdot 86$ & 0.51 & 0.097 \\
\hline Fat oxidation $(\mathrm{g} / \mathrm{h})$ & 2.93 & 0.30 & 3.52 & 0.22 & 0.054 \\
\hline
\end{tabular}

${ }^{\text {*}}$ For details of subjects and procedures, see Methods and Table 1.
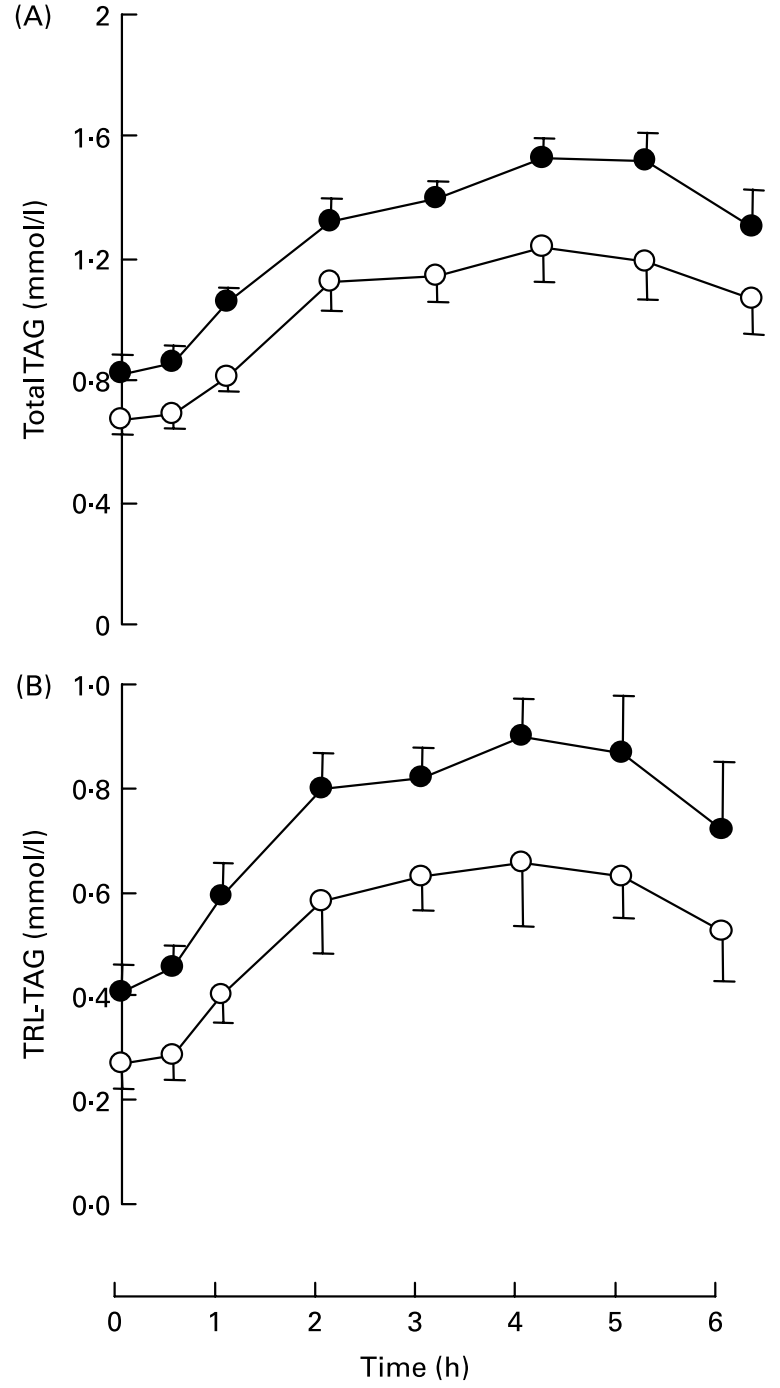

Fig. 1. Concentrations of total plasma TAG (A) and TAG in the TAG-rich lipoproteins (TRL-TAG) (B) following the test meal the day after the control (•) and exercise plus diet $(O)$ interventions. Values are means with their standard errors depicted by vertical bars. Mean values were significantly different from those after the control intervention (repeated measures ANOVA): $P=0.001$.

TRL-TAG concentrations were significantly lower the day after the exercise plus diet compared to the control intervention $(P<0.01)$. On average, total responses of plasma TAG and TRL-TAG to the test meal were 19 and $27 \%$ lower $(P<0.01)$, respectively, the day after exercise plus diet compared to the control trial, whereas incremental responses were not different (Table 4). Peak plasma TAG and TRLTAG responses were 18 and $22 \%$ lower, respectively, after exercise plus diet compared to the control condition (Table 4).

Serum insulin, plasma glucose and NEFA concentrations during the postprandial period are shown in Fig. 2. ANOVA for repeated measures did not reveal any significant differences between trials in these variables $(P>0 \cdot 05)$. Moreover, total, incremental and peak responses of insulin, glucose and NEFA were not significantly different between trials (Table 4).

There were no significant differences between trials in postprandial oxygen consumption, RQ, energy expenditure or substrate oxidation (Table 3 ). 
Table 4. Summary responses of total plasma TAG, TAG in the TAG-rich lipoproteins (TRL-TAG), glucose, NEFA and serum insulin the day after the control and exercise plus diet interventions*

(Mean values with their standard errors)

\begin{tabular}{|c|c|c|c|c|c|}
\hline & \multicolumn{2}{|c|}{ Control } & \multicolumn{2}{|c|}{ Exercise plus diet } & \multirow[b]{2}{*}{$P$ value } \\
\hline & Mean & SEM & Mean & SEM & \\
\hline Total TAG response $(\mathrm{mmol} / / \mathrm{per} \mathrm{h})$ & $1 \cdot 31$ & 0.04 & 1.06 & 0.08 & 0.003 \\
\hline Incremental TAG response $(\mathrm{mmol} / / \mathrm{l}$ per $\mathrm{h})$ & 0.49 & 0.08 & 0.39 & 0.06 & 0.334 \\
\hline Peak TAG response $(\mathrm{mmol} / \mathrm{l})$ & 1.63 & 0.07 & 1.34 & 0.09 & 0.024 \\
\hline Total TRL-TAG response $(\mathrm{mmol} / /$ per $\mathrm{h})$ & 0.75 & 0.06 & 0.55 & 0.07 & 0.003 \\
\hline Incremental TRL-TAG response (mmol//l per $\mathrm{h}$ ) & 0.34 & 0.06 & 0.27 & 0.06 & 0.387 \\
\hline Peak TRL-TAG response $(\mathrm{mmol} / \mathrm{l})$ & 1.00 & 0.07 & 0.78 & 0.09 & 0.008 \\
\hline Total glucose response $(\mathrm{mmol} / \mathrm{l}$ per $\mathrm{h})$ & 5.66 & 0.20 & 5.54 & 0.16 & 0.385 \\
\hline Incremental glucose response $(\mathrm{mmol} / /$ per $\mathrm{h})$ & 0.44 & 0.11 & 0.40 & $0 \cdot 10$ & 0.746 \\
\hline Peak glucose response $(\mathrm{mmol} / \mathrm{l})$ & 6.30 & 0.31 & $6 \cdot 36$ & 0.26 & 0.829 \\
\hline Total insulin response $(\mathrm{mmol} / \mathrm{l}$ per $\mathrm{h})$ & $129 \cdot 4$ & $21 \cdot 7$ & 98.5 & 11.5 & 0.068 \\
\hline Incremental insulin response $(\mathrm{mmol} / \mathrm{l}$ per $\mathrm{h})$ & $67 \cdot 7$ & 13.6 & 74.0 & $10 \cdot 9$ & 0.410 \\
\hline Peak insulin response (pmol/l) & $345 \cdot 1$ & 64.7 & 285.4 & $44 \cdot 1$ & 0.234 \\
\hline Total NEFA response $(\mathrm{mmol} / / \mathrm{l}$ per $\mathrm{h})$ & 0.47 & 0.03 & 0.50 & 0.04 & 0.313 \\
\hline Incremental NEFA response $(\mathrm{mmol} / / \mathrm{l}$ per $\mathrm{h})$ & -0.06 & 0.06 & -0.06 & 0.05 & 0.994 \\
\hline Peak NEFA response (mmol/l) & 0.82 & 0.07 & 0.77 & 0.06 & 0.280 \\
\hline
\end{tabular}

${ }^{*}$ For details of subjects and procedures, see Methods and Table 1

\section{Discussion}

The purpose of the present study was to investigate fasting and postprandial TAG responses to acute moderate negative energy balance (approximately $2.5 \mathrm{MJ}$ ), induced by a combination of exercise of low energy cost and mild energy intake restriction in young, healthy, sedentary women. We observed an approximately $20 \%$ decrease in fasting and postprandial total plasma TAG concentrations the morning after a single bout of light exercise ( $100 \mathrm{~min}$ at $30 \% \mathrm{~V}_{\text {O2peak }}$ ) coupled with mild energy intake restriction of $1.4 \mathrm{MJ}$. This effect was entirely attributed to an approximately $30 \%$ decrease in fasting and postprandial plasma TAG concentrations in the TRL fraction. Therefore, the present data suggest that low energy expenditure exercise along with mild hypoenergetic diet may be a practical and feasible intervention to attenuate fasting and postprandial triacylglycerolaemia.

In the present study, the total energy deficit induced by exercise plus diet compared with the control condition was approximately $2.5 \mathrm{MJ}$ (i.e. about $1 \mathrm{MJ}$ from exercise and about $1.5 \mathrm{MJ}$ from energy intake restriction). The present results are in agreement with previous studies using simi$\operatorname{lar}^{(21,40)}$ or higher ${ }^{(11-14,19)}$ energy deficits induced solely by exercise of longer duration and/or greater intensity. On the other hand, studies in which the exercise-induced energy deficit was equivalent to the exercise-induced energy deficit in the present study $(1 \cdot 0-1.7 \mathrm{MJ})$, i.e. without the added dietinduced energy deficit, have consistently failed to observe a TAG-lowering effect of exercise in the fasting and postprandial states ${ }^{(18,20,21)}$. Likewise, limited available evidence also indicates that an acute, diet-induced energy deficit equivalent to that in the present study (approximately $1.5 \mathrm{MJ}$ ) does not affect fasting and postprandial TAG concentrations ${ }^{(41)}$. Furthermore, studies that examined the effect of exercise with or without compensating for the energy expended during exercise by overfeeding, reported either an abolishment of the TAG-lowering effect of exercise ${ }^{(11)}$ or not $^{(42)}$. The present findings imply that the negative energy balance is the key factor mediating the hypotriacylglycerolaemic effect, whereas the means by which this is accomplished, i.e. increased energy expenditure through exercise or decreased energy intake through hypoenergetic diet, may be of secondary importance. Hence people who find it difficult to exercise at moderateto-high intensities or for prolonged periods of time, e.g. those who are sedentary, can make up for the lower exercise-induced energy expenditure by a mild restriction in energy intake.

We did not observe an effect of exercise plus diet on incremental TAG responses in the postprandial state, suggesting that the reduction in TAG concentrations in the fed condition was primarily due to the lowering of fasting TAG concentrations. This is consistent with the results from several other studies that examined the effects of exercise alone ${ }^{(11,43,44)}$. The smaller fasting plasma TAG pool size likely results in reduced competition between endogenous (VLDL) and exogenous (chylomicrons) lipoproteins for lipoprotein lipase (LPL)-mediated hydrolysis in the fed state $^{(45-47)}$, thereby enhancing the clearance of postprandial TRL-TAG, which may underlie the reduction in postprandial TAG concentrations after exercise. In fact, it has been shown previously that the reduction in postprandial TAG concentrations after a single bout of exercise is predominantly, if not exclusively, due to reduced VLDL-TAG concentrations ${ }^{(13,14,48)}$. Likewise, we did not observe any differences in postprandial insulin concentrations. This is in accordance with studies that examined the effect of similar exercise sessions ${ }^{(18,19)}$, suggesting that exercise-induced TAG-lowering is not mediated by an increase in insulin sensitivity ${ }^{(34)}$. Furthermore, many investigators have observed substantial reductions in postprandial triacylglycerolaemia without any accompanying changes in postprandial glucose ${ }^{(12-14,16,18)}$ or $\operatorname{NEFA}^{(13,14,16,18)}$ concentrations, in agreement with the present observations.

The hypotriacylglycerolaemic effect of prolonged moderate-intensity exercise has been attributed in part to increased LPL activity ${ }^{(7)}$, i.e. the key enzyme responsible for circulating 

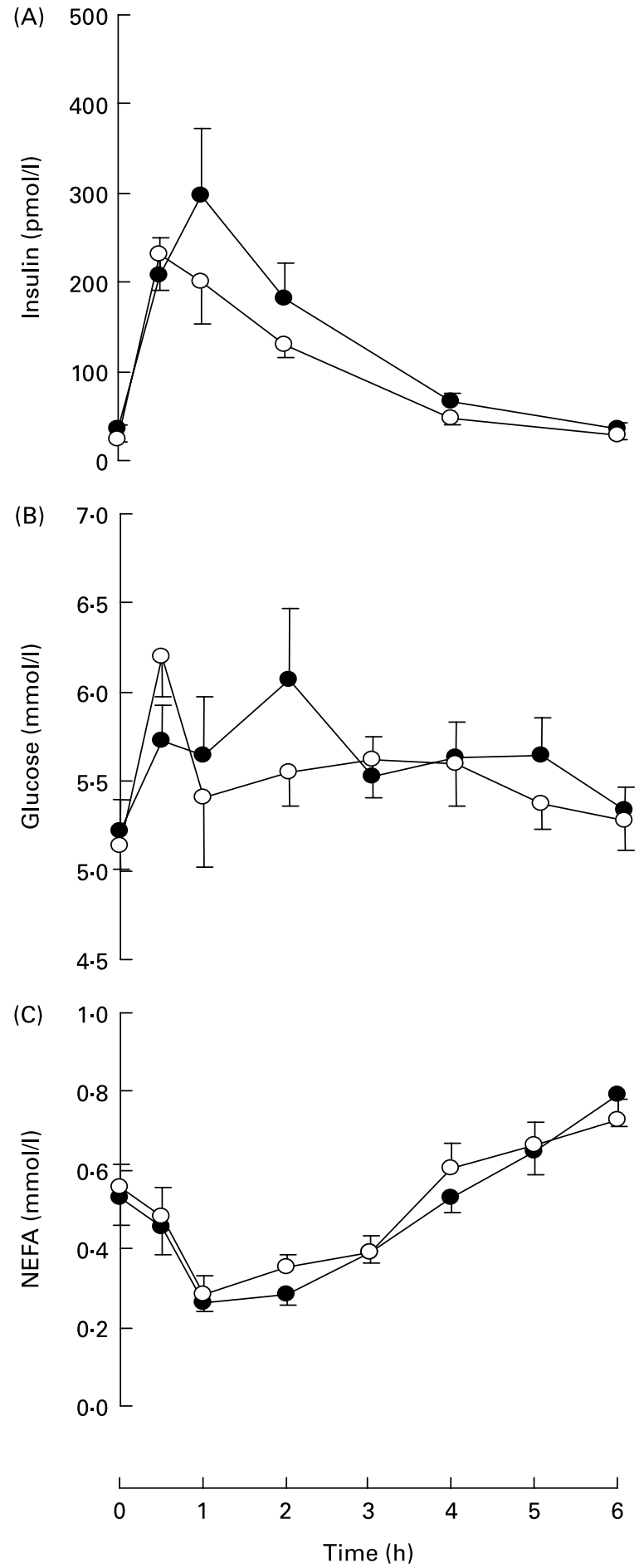

Fig. 2. Concentrations of serum insulin (A), plasma glucose (B) and NEFA (C) following the test meal the day after the control $(\bullet)$ and exercise plus diet $(O)$ interventions. Values are means with their standard errors depicted by vertical bars. Mean values were significantly different from those after the control intervention (repeated measures ANOVA): (A) $P=0.114$; (B) $P=0.498$; (C) $P=0.387$.

TAG hydrolysis. This increase is delayed and is located mainly in skeletal muscle ${ }^{(49,50)}$ and not in adipose tissue $e^{(51)}$. Increased LPL-mediated hydrolysis likely results in augmented clearance of TRL-TAG across skeletal muscle in fasting ${ }^{(52)}$ and postprandial states ${ }^{(14)}$, presumably in order to replenish intramuscular TAG stores that were depleted by prior exercise ${ }^{(50,53)}$. Studies which evaluated whole-body endogenous $^{(15,54)}$ and exogenous ${ }^{(55)}$ TAG clearance the day after a prolonged $(2-3 \mathrm{~h})$ bout of moderate-intensity exercise found significantly augmented removal rates of plasma TAG compared with resting conditions and significantly reduced plasma TAG concentrations. However, shorter exercise bouts (60-90 min) at the same intensity, corresponding to lower energy expenditures, do not affect the clearance of either endogenous $^{(56)}$ or exogenous ${ }^{(13,55)}$ TAG, even though such exercise bouts may still reduce fasting and postprandial TAG concentrations ${ }^{(13,55)}$. It has been suggested, therefore, that exercise may also suppress TAG production by the liver ${ }^{(57)}$, an assertion supported by the much higher ketone body (3-hydroxybuturate) concentrations the morning after a single bout of evening exercise ${ }^{(12,14,15)}$, implying increased hepatic fatty acid oxidation and presumably reduced availability of fatty acids for esterification and TAG synthesis. In the present study, postprandial whole-body fat oxidation tended to be higher $(P=0.054)$ the day after exercise plus diet. However, it is unlikely that this contributed to the observed hypotriacylglycerolaemia, since there are reports of increased whole-body fat oxidation the day after exercise without any changes in fasting and postprandial TAG concentrations $^{(11)}$, and also reports of reduced TAG concentrations with no changes in substrate oxidation ${ }^{(16)}$. Furthermore, although a suppressive effect of exercise on hepatic TAG secretion has indeed been observed in animals ${ }^{(58,59)}$, isotope tracer kinetic studies in human subjects have consistently failed to provide support for this hypothesis ${ }^{(15,54)}$.

Prolonged moderate energy restriction leading to weight loss is known to reduce fasting and postprandial plasma TAG concentrations ${ }^{(60-63)}$. Whether this is attributed to the negative energy balance or the accompanying weight loss is not clear; however, considerable weight loss induced by several weeks of moderate energy intake restriction does not affect fasting and postprandial plasma TAG concentrations when TAG metabolism is evaluated after a period of weight stability, i.e. when the effects of acute energy intake restriction are not present ${ }^{(64,65)}$. Effects on LPL activity have also been implicated in the diet-induced lowering of plasma TAG concentrations. Prolonged intense energy intake restriction $(10 \mathrm{~d}$ on a $1674 \mathrm{~kJ}$ ( $400 \mathrm{kcal}) \mathrm{diet})$ reduces fasting but increases postprandial LPL activity in adipose tissue ${ }^{(66)}$, possibly in order to replenish body energy stores when dietary energy becomes available. Similarly, acute intense energy restriction $(2 \mathrm{~d}$ on a $1674 \mathrm{~kJ}(400 \mathrm{kcal})$ diet $)$ decreases fasting LPL activity in adipose tissue but increases fasting LPL activity in skeletal muscle, thus resulting in augmented TAG removal capacity across muscle ${ }^{(67)}$. Studies in rodents also suggest that prolonged energy intake restriction decreases fasting but increases postprandial LPL activity in adipose tissue, and increases fasting without affecting postprandial LPL activity in skeletal muscle ${ }^{(68)}$. Though these observations suggest that energy intake restriction lowers plasma TAG concentrations by enhancing intravascular TAG hydrolysis, nonetheless, kinetic studies in man indicate that long-term hypoenergetic diet leading to weight loss lowers plasma TAG concentrations by attenuating hepatic TAG secretion without affecting TAG removal from the circulation ${ }^{(69,70)}$. There are no similar studies on the effects of acute mild energy intake restriction. 
Both exercise and energy intake restriction may therefore attenuate triacylglycerolaemia, though possibly via different mechanisms. Exercise-induced TAG lowering likely results from enhanced removal rate of TAG from the core of circulating $\operatorname{TRL}^{(15,54,55)}$, whereas hypoenergetic diet-induced lowering of plasma TAG concentrations likely results from reduced secretion rate of TAG from the liver ${ }^{(69,70)}$. The mechanisms leading to exercise-induced hypotriacylglycerolaemia are threshold-dependent and do not manifest after exercise of low-to-moderate energy expenditure ${ }^{(55,56)}$, whereas similar information regarding the effects of energy intake restriction is not available. The observation that a single session of light exercise in conjunction with acute mild energy intake restriction leads to decreased fasting and postprandial TAG concentrations (present study), whereas each one in itself does not ${ }^{(18,41)}$, suggests an additive effect of diet and exercise on fasting and postprandial TAG metabolism, mediated largely by the cumulative energy deficit and the resulting negative energy balance, and is likely the result of a combination of increased TAG removal (due to exercise) and decreased TAG secretion (due to energy intake restriction). This hypothesis has never been put to test.

This is the first study to investigate the acute effects of exercise along with energy intake restriction on fasting and postprandial TAG metabolism. Previous studies have examined exercise alone $\mathrm{e}^{(12-14,16-19)}$, or diet alone ${ }^{(41)}$, or exercise in conjunction with hyperenergetic diet to maintain zero energy balance $^{(11,42)}$. A combination of low energy expenditure exercise plus mild hypoenergetic diet may be more practical and feasible than exercise alone, especially for people who cannot exercise for prolonged periods of time at moderate-to-high intensities, such as many sedentary individuals. A reduction in energy intake, such as that in the present study, can readily be achieved though a minor reduction in portion size, or a reduction of about $30 \mathrm{~g}$ of medium-fat meat (about $335 \mathrm{~kJ}$ ), one slice $(30 \mathrm{~g})$ of bread (about $335 \mathrm{~kJ}$ ), two tablespoons $(10 \mathrm{~g})$ of butter (about $300 \mathrm{~kJ})$ and one cup $(250 \mathrm{ml})$ of soft drink (about $420 \mathrm{~kJ}$ ), whereas an increase in energy expenditure, such as that in the present study, can be accomplished by light walking for $100 \mathrm{~min}$. Since the benefits of exercise on TAG metabolism are equal ${ }^{(71,72)}$ or greater $^{(20)}$ when exercise is intermittent compared to continuous, this exercise time is easy to achieve within the day, as it may include, for example, a 40 min walk for transportation to and from work, and a $1 \mathrm{~h}$ walk during leisure time (e.g. a walk to the market).

In conclusion, one bout of light exercise along with mild energy intake restriction decreases fasting and postprandial total plasma and TRL-TAG concentrations in young, healthy, sedentary women. Further studies are needed to elucidate the underlying mechanisms, the duration of these effects, and the effectiveness in populations such as the obese and diabetics, i.e. those at high risk for hypertriacylglycerolaemia.

\section{Acknowledgements}

The authors would like to thank Yannis Tsekouras, Costas Anastasiou and Antigoni Tsiafitsa for technical support and all participants for their collaboration. M. M. was supported by the Greek Governmental Institute of Scholarships. This study was partially supported by the Harokopio Graduate School. M. M. conceived the study and was involved in the study design and implementation, data collection, analysis and interpretation, supervised all fieldwork and drafted the manuscript. N. C. and $\mathrm{N}$. A. were involved in the study implementation and data collection and analysis. F. M. was involved in the study design, data interpretation and manuscript writing. K. P. S. supervised blood analysis. D. P. was involved in data statistical analysis and interpretation and edited the manuscript. S. A. K. was involved in the study design, co-ordinated the fieldwork and performed the venous cannulations. L. S. S. was involved in the study design, data interpretation, manuscript writing and in overall supervision of the study. All authors read and approved the final manuscript. None of the authors had a conflict of interest regarding any aspect of this research.

\section{References}

1. Thom T, Haase N, Rosamond W, et al. (2006) Heart disease and stroke statistics - 2006 update: a report from the American Heart Association Statistics Committee and Stroke Statistics Subcommittee. Circulation 113, e85-e151.

2. Sans S, Kesteloot H \& Kromhout D (1997) The burden of cardiovascular diseases mortality in Europe. Task Force of the European Society of Cardiology on Cardiovascular Mortality and Morbidity Statistics in Europe. Eur Heart J 18, 1231-1248.

3. Patel A, Barzi F, Jamrozik K, Lam TH, Ueshima H, Whitlock G \& Woodward M (2004) Serum triglycerides as a risk factor for cardiovascular diseases in the Asia-Pacific region. Circulation 110, 2678-2686.

4. Gotto $\mathrm{AM} \mathrm{Jr}$ (1998) Triglyceride as a risk factor for coronary artery disease. Am J Cardiol 82, 22Q-25Q.

5. Karpe F (1999) Postprandial lipoprotein metabolism and atherosclerosis. J Intern Med 246, 341-355.

6. Roche HM \& Gibney MJ (2000) The impact of postprandial lipemia in accelerating atherothrombosis. J Cardiovasc Risk 7, 317-324.

7. Gill JM \& Hardman AE (2003) Exercise and postprandial lipid metabolism: an update on potential mechanisms and interactions with high-carbohydrate diets (review). J Nutr Biochem 14, $122-132$.

8. Durstine JL, Grandjean PW, Cox CA \& Thompson PD (2002) Lipids, lipoproteins, and exercise. J Cardiopulm Rehabil 22, 385-398.

9. Thompson PD, Crouse SF, Goodpaster B, Kelley D, Moyna N $\&$ Pescatello L (2001) The acute versus the chronic response to exercise. Med Sci Sports Exerc 33, S438-S445.

10. Petitt DS \& Cureton KJ (2003) Effects of prior exercise on postprandial lipemia: a quantitative review. Metabolism 52, 418-424.

11. Burton FL, Malkova D, Caslake MJ \& Gill JM (2008) Energy replacement attenuates the effects of prior moderate exercise on postprandial metabolism in overweight/obese men. Int $J$ Obes (Lond) 32, 481-489.

12. Gill JM, Frayn KN, Wootton SA, Miller GJ \& Hardman AE (2001) Effects of prior moderate exercise on exogenous and endogenous lipid metabolism and plasma factor VII activity. Clin Sci (Lond) 100, 517-527.

13. Gill JM, Mees GP, Frayn KN \& Hardman AE (2001) Moderate exercise, postprandial lipaemia and triacylglycerol clearance. Eur J Clin Invest 31, 201-207.

14. Malkova D, Evans RD, Frayn KN, Humphreys SM, Jones PR \& Hardman AE (2000) Prior exercise and postprandial substrate extraction across the human leg. Am J Physiol Endocrinol Metab 279, E1020-E1028.

15. Tsekouras YE, Yanni AE, Bougatsas D, Kavouras SA \& Sidossis LS (2007) A single bout of brisk walking increases 
basal very low-density lipoprotein triacylglycerol clearance in young men. Metabolism 56, 1037-1043.

16. Herd SL, Kiens B, Boobis LH \& Hardman AE (2001) Moderate exercise, postprandial lipemia, and skeletal muscle lipoprotein lipase activity. Metabolism 50, 756-762.

17. Malkova D, Hardman AE, Bowness RJ \& Macdonald IA (1999) The reduction in postprandial lipemia after exercise is independent of the relative contributions of fat and carbohydrate to energy metabolism during exercise. Metabolism 48, 245-251.

18. Tsetsonis NV \& Hardman AE (1996) Effects of low and moderate intensity treadmill walking on postprandial lipaemia in healthy young adults. Eur J Appl Physiol Occup Physiol 73, 419-426.

19. Tsetsonis NV \& Hardman AE (1996) Reduction in postprandial lipemia after walking: influence of exercise intensity. Med Sci Sports Exerc 28, 1235-1242.

20. Altena TS, Michaelson JL, Ball SD \& Thomas TR (2004) Single sessions of intermittent and continuous exercise and postprandial lipemia. Med Sci Sports Exerc 36, 1364-1371.

21. Zhang JQ, Ji LL, Fogt DL \& Fretwell VS (2007) Effect of exercise duration on postprandial hypertriglyceridemia in men with metabolic syndrome. $J$ Appl Physiol 103, 1339-1345.

22. Pfeiffer M, Wenk C \& Colombani PC (2006) The influence of 30 minutes of light to moderate intensity cycling on postprandial lipemia. Eur J Cardiovasc Prev Rehabil 13, 363-368.

23. Crouse SF, O'Brien BC, Rohack JJ, Lowe RC, Green JS, Tolson H \& Reed JL (1995) Changes in serum lipids and apolipoproteins after exercise in men with high cholesterol: influence of intensity. J Appl Physiol 79, 279-286.

24. Aldred HE, Perry IC \& Hardman AE (1994) The effect of a single bout of brisk walking on postprandial lipemia in normolipidemic young adults. Metabolism 43, 836-841.

25. Petitt DS, Arngrimsson SA \& Cureton KJ (2003) Effect of resistance exercise on postprandial lipemia. J Appl Physiol 94, $694-700$.

26. US Department of Health and Human Services (1996) Physical Activity and Health: A Report of the Surgeon General. Atlanta, GA: US Department of Health and Human Services, Centers for Disease Control and Prevention, National Center for Chronic Disease Prevention and Health Promotion.

27. Ekkekakis P \& Petruzzello SJ (1999) Acute aerobic exercise and affect: current status, problems and prospects regarding doseresponse. Sports Med 28, 337-374.

28. White SA, Croce RV, Loureiro EM \& Vroman N (1991) Effects of frequency and duration of exercise sessions on physical activity levels and adherence. Percept Mot Skills 73, $172-174$.

29. Keller C \& Trevino RP (2001) Effects of two frequencies of walking on cardiovascular risk factor reduction in Mexican American women. Res Nurs Health 24, 390-401.

30. Taylor HL, Buskirk E \& Henschel A (1955) Maximal oxygen intake as an objective measure of cardio-respiratory performance. J Appl Physiol 8, 73-80.

31. American College of Sports Medicine (2000) ACSM's Guidelines for Exercise Testing and Prescription, 6th ed. Philadelphia: Lippincott Williams \& Wilkins.

32. Gill JM, Malkova D \& Hardman AE (2005) Reproducibility of an oral fat tolerance test is influenced by phase of menstrual cycle. Horm Metab Res 37, 336-341.

33. Lin PH, Proschan MA, Bray GA, Fernandez CP, Hoben K, Most-Windhauser M, Karanja N \& Obarzanek E (2003) Estimation of energy requirements in a controlled feeding trial. Am J Clin Nutr 77, 639-645.

34. Gill JM, Herd SL, Tsetsonis NV \& Hardman AE (2002) Are the reductions in triacylglycerol and insulin levels after exercise related? Clin Sci (Lond) 102, 223-231.

35. Koutsari C, Karpe F, Humphreys SM, Frayn KN \& Hardman AE (2001) Exercise prevents the accumulation of triglyceride-rich lipoproteins and their remnants seen when changing to a high-carbohydrate diet. Arterioscler Thromb Vasc Biol 21, $1520-1525$.

36. Weir JB (1949) New methods for calculating metabolic rate with special reference to protein metabolism. J Physiol 109, 1-9.

37. Peronnet F \& Massicotte D (1991) Table of nonprotein respiratory quotient: an update. Can J Sport Sci 16, 23-29.

38. Matthews DR, Hosker JP, Rudenski AS, Naylor BA, Treacher DF \& Turner RC (1985) Homeostasis model assessment: insulin resistance and beta-cell function from fasting plasma glucose and insulin concentrations in man. Diabetologia 28, 412-419.

39. Friedewald WT, Levy RI \& Fredrickson DS (1972) Estimation of the concentration of low-density lipoprotein cholesterol in plasma, without use of the preparative ultracentrifuge. Clin Chem 18, 499-502.

40. Gill JM, Al-Mamari A, Ferrell WR, Cleland SJ, Packard CJ, Sattar N, Petrie JR \& Caslake MJ (2004) Effects of prior moderate exercise on postprandial metabolism and vascular function in lean and centrally obese men. J Am Coll Cardiol 44, 2375-2382.

41. Gill JM \& Hardman AE (2000) Postprandial lipemia: effects of exercise and restriction of energy intake compared. Am J Clin Nutr 71, 465-471.

42. Gyntelberg F, Brennan R, Holloszy JO, Schonfeld G, Rennie MJ \& Weidman SW (1977) Plasma triglyceride lowering by exercise despite increased food intake in patients with type IV hyperlipoproteinemia. Am J Clin Nutr 30, 716-720.

43. Kokalas N, Petridou A, Nikolaidis MG \& Mougios V (2005) Effect of aerobic exercise on lipaemia and its fatty acid profile after a meal of moderate fat content in eumenorrhoeic women. Br J Nutr 94, 698-704.

44. Kolifa M, Petridou A \& Mougios V (2004) Effect of prior exercise on lipemia after a meal of moderate fat content. Eur $J$ Clin Nutr 58, 1327-1335.

45. Brunzell JD, Hazzard WR, Porte D Jr \& Bierman EL (1973) Evidence for a common, saturable, triglyceride removal mechanism for chylomicrons and very low density lipoproteins in man. J Clin Invest 52, 1578-1585.

46. Bjorkegren J, Packard CJ, Hamsten A, Bedford D, Caslake M, Foster L, Shepherd J, Stewart P \& Karpe F (1996) Accumulation of large very low density lipoprotein in plasma during intravenous infusion of a chylomicron-like triglyceride emulsion reflects competition for a common lipolytic pathway. J Lipid Res 37, 76-86.

47. Fisher RM, Coppack SW, Humphreys SM, Gibbons GF \& Frayn KN (1995) Human triacylglycerol-rich lipoprotein subfractions as substrates for lipoprotein lipase. Clin Chim Acta 236, 7-17.

48. Gill JM, Al-Mamari A, Ferrell WR, Cleland SJ, Sattar N, Packard CJ, Petrie JR \& Caslake MJ (2006) Effects of a moderate exercise session on postprandial lipoproteins, apolipoproteins and lipoprotein remnants in middle-aged men. Atherosclerosis 185, 87-96.

49. Seip RL, Mair K, Cole TG \& Semenkovich CF (1997) Induction of human skeletal muscle lipoprotein lipase gene expression by short-term exercise is transient. Am J Physiol 272, E255-E261.

50. Kiens B \& Richter EA (1998) Utilization of skeletal muscle triacylglycerol during postexercise recovery in humans. Am J Physiol 275, E332-E337.

51. Seip RL, Angelopoulos TJ \& Semenkovich CF (1995) Exercise induces human lipoprotein lipase gene expression in skeletal muscle but not adipose tissue. Am J Physiol 268, E229-E236.

52. Kiens B, Lithell H, Mikines KJ \& Richter EA (1989) Effects of insulin and exercise on muscle lipoprotein lipase activity in man and its relation to insulin action. J Clin Invest 84, 1124-1129.

53. van Loon LJ (2004) Use of intramuscular triacylglycerol as a substrate source during exercise in humans. J Appl Physiol 97, $1170-1187$. 
54. Magkos F, Wright DC, Patterson BW, Mohammed BS \& Mittendorfer B (2006) Lipid metabolism response to a single, prolonged bout of endurance exercise in healthy young men. Am J Physiol Endocrinol Metab 290, E355-E362.

55. Annuzzi G, Jansson E, Kaijser L, Holmquist L \& Carlson LA (1987) Increased removal rate of exogenous triglycerides after prolonged exercise in man: time course and effect of exercise duration. Metabolism 36, 438-443.

56. Magkos F, Patterson BW, Mohammed BS \& Mittendorfer B (2007) A single 1-h bout of evening exercise increases basal FFA flux without affecting VLDL-triglyceride and VLDL-apolipoprotein B-100 kinetics in untrained lean men. Am J Physiol Endocrinol Metab 292, E1568-E1574.

57. Gill JM, Al-Mamari A, Ferrell WR, Cleland SJ, Sattar N, Packard CJ, Petrie JR \& Caslake MJ (2006) Effects of a moderate exercise session on postprandial lipoproteins, apolipoproteins and lipoprotein remnants in middle-aged men. Atherosclerosis 185, 87-96.

58. Simonelli C \& Eaton RP (1978) Reduced triglyceride secretion: a metabolic consequence of chronic exercise. Am J Physiol 234, E221-E227.

59. Mondon CE, Dolkas CB, Tobey T \& Reaven GM (1984) Causes of the triglyceride-lowering effect of exercise training in rats. J Appl Physiol 57, 1466-1471.

60. Sharman MJ, Gomez AL, Kraemer WJ \& Volek JS (2004) Very low-carbohydrate and low-fat diets affect fasting lipids and postprandial lipemia differently in overweight men. $J$ Nutr 134, 880-885.

61. Volek JS, Sharman MJ, Gomez AL, DiPasquale C, Roti M, Pumerantz A \& Kraemer WJ (2004) Comparison of a very low-carbohydrate and low-fat diet on fasting lipids, LDL subclasses, insulin resistance, and postprandial lipemic responses in overweight women. $J$ Am Coll Nutr 23, 177-184.

62. Volek JS, Gomez AL \& Kraemer WJ (2000) Fasting lipoprotein and postprandial triacylglycerol responses to a low-carbohydrate diet supplemented with $n-3$ fatty acids. J Am Coll Nutr 19, 383-391.
63. Ybarra J, James RW, Makoundou V, Bioletto S \& Golay A (2001) Effects of short-term modest weight loss on fasting and post-prandial lipoprotein sub-fractions in type 2 diabetes mellitus patients. Diabetes Metab 27, 701-708.

64. James AP, Watts GF, Barrett PH, Smith D, Pal S, Chan DC \& Mamo JC (2003) Effect of weight loss on postprandial lipemia and low-density lipoprotein receptor binding in overweight men. Metabolism 52, 136-141.

65. Kelley DE, Wing R, Buonocore C, Sturis J, Polonsky K \& Fitzsimmons M (1993) Relative effects of calorie restriction and weight loss in noninsulin-dependent diabetes mellitus. J Clin Endocrinol Metab 77, 1287-1293.

66. Taskinen MR \& Nikkila EA (1987) Basal and postprandial lipoprotein lipase activity in adipose tissue during caloric restriction and refeeding. Metabolism 36, 625-630.

67. Taskinen MR \& Nikkila EA (1979) Effects of caloric restriction on lipid metabolism in man: changes of tissue lipoprotein lipase activities and of serum lipoproteins. Atherosclerosis 32, 289-299.

68. Quig DW, Layman DK, Bechtel PJ \& Hackler LR (1983) The influence of starvation and refeeding on the lipoprotein lipase activity of skeletal muscle and adipose tissue of lean and obese Zucker rats. J Nutr 113, 1150-1156.

69. Mittendorfer B, Patterson BW \& Klein S (2003) Effect of weight loss on VLDL-triglyceride and apoB-100 kinetics in women with abdominal obesity. Am J Physiol Endocrinol Metab 284, E549-E556.

70. Ginsberg HN, Le NA \& Gibson JC (1985) Regulation of the production and catabolism of plasma low density lipoproteins in hypertriglyceridemic subjects. Effect of weight loss. J Clin Invest 75, 614-623.

71. Murphy MH, Nevill AM \& Hardman AE (2000) Different patterns of brisk walking are equally effective in decreasing postprandial lipaemia. Int J Obes Relat Metab Disord 24, 1303-1309.

72. Gill JM, Murphy MH \& Hardman AE (1998) Postprandial lipemia: effects of intermittent versus continuous exercise. Med Sci Sports Exerc 30, 1515-1520. 